\title{
Fuzzy based Decision Support Model for Irrigation System Management
}

\author{
Amthal K. Mousa \\ University of Technology, \\ Baghdad, Iraq
}

\author{
Muayad S. Croock, Ph.D \\ University of Technology, \\ Baghdad, Iraq
}

\author{
Mohammed N. Abdullah, Ph.D \\ University of Technology, \\ Baghdad, Iraq
}

\begin{abstract}
In this paper, an efficient irrigation system is proposed based on computing evapotranspiration (ET) and the required irrigation quantity using fuzzy inference methodology. The aim of this system is to schedule irrigation according to the particular requirements of a crop and to the change in various climatological parameters and other factors. This is to avoid over- or under-watering which significantly affects the crop quality and yields using the proposed algorithm. Moreover, our algorithm reduces the power switching, hence it conserves energy. The results demonstrate that the fuzzy model is a quick and accurate tool for calculating evapotranspiration as well as the required net irrigation. Besides, no water stress occurs because our model prohibits depletion in soil moisture from reaching $100 \%$ which represents permanent wilting point. Since, irrigation always starts when depletion ratio reaches $50 \%$ of total available soil moisture. Additionally, we introduce a general algorithm as a part of the proposed system to calculate the irrigation time, which well suits both micro-irrigation methods: sprinkler and drip irrigation.
\end{abstract}

\section{Keywords}

Deficit irrigation, evapotranspiration, FIS, fuzzy, Matlab.

\section{INTRODUCTION}

The rationale behind an efficient irrigation program is to reduce water waste caused by deep percolation and runoff, while supplying the crop with sufficient amount of water. Therefore, a smart scheduling and efficient irrigation method are considered. In agricultural, the superior water system requires real estimation of crop water needed by plants depending on different factors, such as evapotranspiration. Evapotranspiration (ET) represents the losing water from both: the soil surface (evaporation) and plants (transpiration). [1]

Several studies have been introduced to prove that soil moisture should remain as close as possible to a desired value [2-4]. This requires frequent ON/OFF switching of the irrigation system power to keep the soil moisture close to this value. Besides, these studies have been proposed irrigation control systems that are mainly based on soil moisture detection. Some studies have considered air temperature effect besides soil moisture detection, regardless of other essential parameters, such as: wind speed, air humidity, radiation, irrigation strategy, irrigation equipment features [5-7].

In this paper, we propose an algorithm that considers all the former factors and guarantees irrigation at critical depletion. Hence, no water stress occurs. Our algorithm follows the standard procedure proposed by [1]. Furthermore, it reduces the power switching, hence it conserves energy. It supports scientifically irrigation according to real need of plants, thus improving the efficiency of water resource consumption. This is done using fuzzy inference system to calculate ET and the sufficient amount of water. Moreover, it is appropriate for both irrigation methods: sprinkler, and drip irrigation.

The layout of the paper can be summarized as: Section 2 explains the description of the proposed system. In Section 3, the specifications of the proposed algorithm are showed. In Section 4, the results have been discussed. Finally, the conclusions are drawn in Section 5 .

\section{DESCRIPTION OF THE PROPOSED SYSTEM}

In this section, the proposed system has been explained. For easing the reading flow, the system description is divided into two parts as follows.

\subsection{Evapotranspiration Model}

ET is a critical parameter that determines the quantity of water to be supplied through irrigation. Several climatological parameters should be taken into consideration when evaluating reference evapotranspiration (ETo), which are: solar radiation, air temperature, air humidity and wind speed. PenmanMonteith equation has generally been considered as a standard method for predicting ETo, which is $[1,2]$ :

$$
\mathrm{ET}_{0}=\frac{0.408 \Delta\left(\mathrm{R}_{\mathrm{n}}-\mathrm{G}\right)+\gamma\left(900 /\left(\mathrm{T}_{\text {mean }+273}\right)\right) \mathrm{u}_{2}\left(\mathrm{e}_{\mathrm{s}}-\mathrm{e}_{\mathrm{a}}\right)}{\Delta+\gamma\left(1+0.34 \mathrm{u}_{2}\right)}
$$

where $\mathrm{ET}_{\mathrm{o}}$ is reference evapotranspiration $\left[\mathrm{mm} \mathrm{day}^{-1}\right], \mathrm{R}_{\mathrm{n}}$ is net radiation at the crop surface $\left[\mathrm{MJ} \mathrm{m}^{-2}\right.$ day $\left.^{-1}\right], \mathrm{G}$ is soil heat flux density $\left[\mathrm{MJ} \mathrm{m}^{-2}\right.$ day $\left.^{-1}\right]$,

$\mathrm{T}$ is mean daily air temperature at $2 \mathrm{~m}$ height $\left[{ }^{\circ} \mathrm{C}\right], \mathrm{u}_{2}$ is wind speed at $2 \mathrm{~m}$ height $\left[\mathrm{m} \mathrm{s}^{-1}\right]$,

$\mathrm{e}_{\mathrm{s}}$ is saturation vapour pressure $[\mathrm{kPa}], \mathrm{e}_{\mathrm{a}}$ actual vapour pressure $[\mathrm{kPa}]$,

$e_{s}-e_{a}$ is saturation vapour pressure deficit $[\mathrm{kPa}]$,

$\Delta$ is slope vapour pressure curve $\left[\mathrm{kPa}^{\circ} \mathrm{C}^{-1}\right]$,

$\gamma$ is psychrometric constant $\left[\mathrm{kPa}{ }^{\circ} \mathrm{C}^{-1}\right]$.

\subsection{Theory of the Fuzzy Inference System}

Fuzzy inference system (FIS) is an approximate reasoning method that could be used to model a process behavior even with incomplete and uncertain information $[8,9]$.

Fuzzy logic can frame the solution to a problem in easily understood expressions, so as to utilize human experience in designing the model. 
The most commonly used methods in fuzzy inference are Mamdani and Sugeno. Sugeno method is chosen, due to its suitability to optimization, adaptive techniques, and mathematical analysis. The defuzzification is done using weighted average method. It is given by the formula [11]:

$$
\mathrm{y}^{\mathrm{l}}=\frac{\sum_{\mathrm{l}=1}^{\mathrm{N}} \mathrm{w}_{\mathrm{i}} \mathrm{z}_{\mathrm{i}}}{\sum_{\mathrm{l}=1}^{\mathrm{N}} \mathrm{w}_{\mathrm{i}}}
$$

where $w_{i}$ is the membership of the output of each rule, $\mathrm{z}_{\mathrm{i}}$ is the weight associated with each rule, $\mathrm{N}$ is the number of rules, and $\mathrm{y}^{1}$ is the defuzzified output.

\section{SPECIFICATION OF THE PROPOSED ALGORITHM}

The proposed approach can be described as an algorithm that composes of four tasks as demonstrated in Figure 1. It simultaneously monitors any variation in the crucial factors and adaptively controls irrigation system according to these changes.

Our algorithm consists of integrating several tasks, each of which is performed, and then its output results are passed to the next stage. This is to perform its individual operations according to the current conditions.

It involves a prediction of a crop water demands with a prediction of the proper amount of water needed according to weather and soil moisture conditions. These conditions are collected from sensors distributed among the specified farm. Moreover, soil moisture state is determined through performing a simultaneous soil detection mechanism.

Additionally, the proposed algorithm schedules the required irrigation intervals and irrigation applied time. In addition, it tunes them according to the applied irrigation strategy; which may be drip or sprinkler irrigation method. Moreover, the proposed algorithm gives the system more ability to choose the used irrigation devices and equipment features, such as: system efficiency, nozzle discharge ratio, pressure, precipitation rate and other important factors that significantly affect the irrigation management mechanism. Finally, the irrigation application time and schedule is executed in the valve of the specified location.

Inputs from sensors

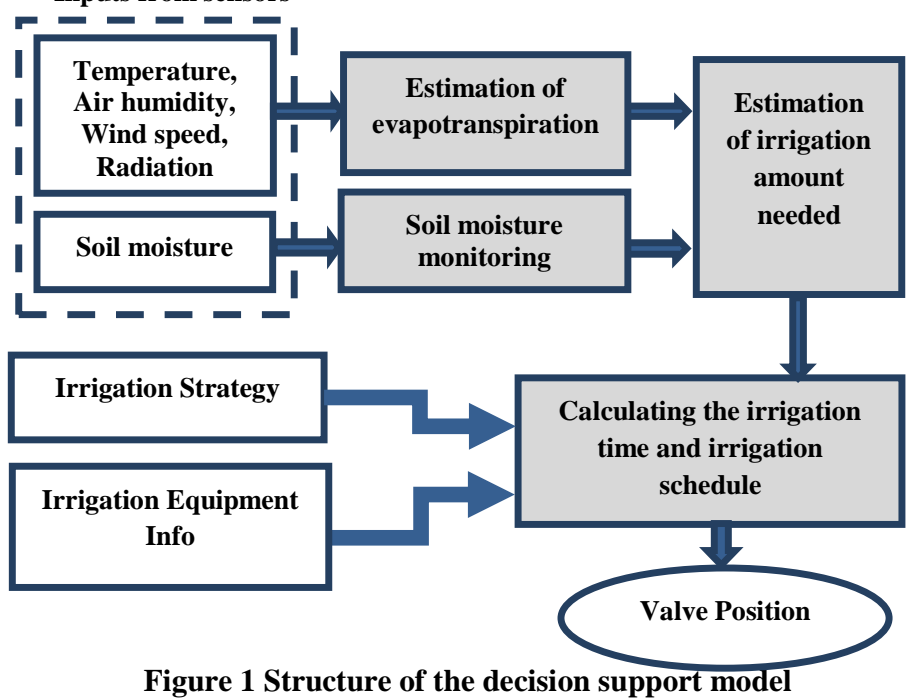

The main four tasks are demonstrated in details as follows.

\subsection{Estimation of Evapotranspiration}

A simple ET0 prediction system is developed based on FIS using Matlab. The input variables of fuzzy system are the weather parameters, which are: air temperature, air humidity, solar radiation and wind speed. The output variable is ET0; Figure 2 shows the proposed fuzzy logic system for computing ET0.

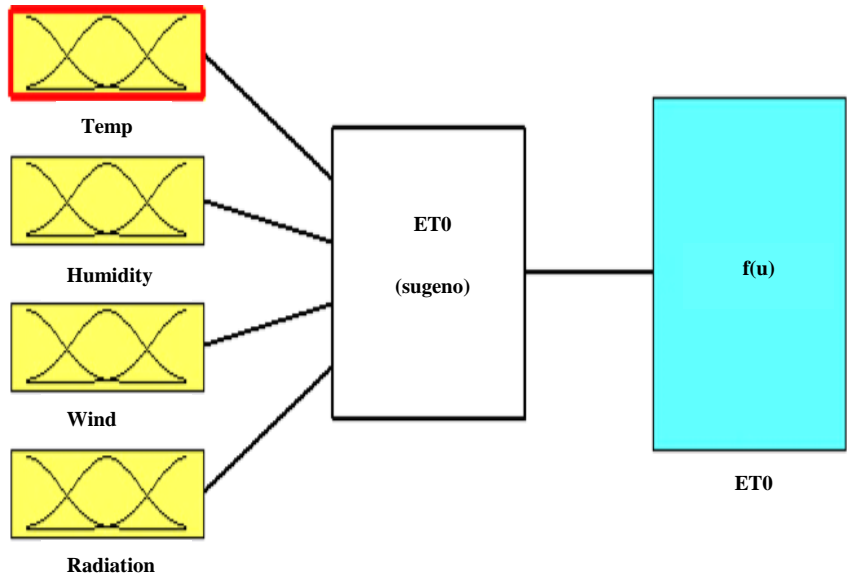

Figure 2 Fuzzy inference system for computing ET0

The universes of discourse of input and output variables are set according to the data generated by New_LocClim software from meteorological station (Baghdad), which are demonstrated as follows.

The universes of discourse of input variable Temp are $\{9,13,17,21,25,29,33\}$. Its fuzzy language values are \{NL (very cold), NM (cold), NS (relatively cold), ZO (moderate), PS (relatively hot), PM (hot) and PB (very hot) $\}$. The universes of discourse of input variable Humidity are $\{25,36.5,48,59.5,71,82.5,94\}$. Its fuzzy language values are \{NL (very dry), NM (dry), NS (relatively dry), ZO (moderate), PS (relatively wet), PM (wet) and PB (very wet)\}. The universes of discourse of input variable Wind are $\{172,189.5,207$, $224.5,242,259.5,277\}$. Its fuzzy language values are \{NL (very slow), NM (slow), NS (relatively slow), ZO (moderate), PS (relatively fast), PM (fast) and PB (very fast)\}. The universes of discourse of input variable Radiation are $\{9,12,15,18,21,24,27\}$. Its fuzzy language values are $\{\mathrm{NL}$ (very low), NM (low), NS (relatively low), ZO (moderate), PS (relatively high), PM (high) and PB (very high)\}. Membership functions of input variables are shown in Figure 3.

The universes of discourse of output variable ET0 are $\{1.19,2.19,3.45,4.43,9.28,7.41,10.13\}$. Its fuzzy language values are \{vSmall (very small), small (small), pSmall (relatively small), medium (moderate), high (relatively high), pHigh (high) and vHigh (very high)\}. Its membership function type is constant. 


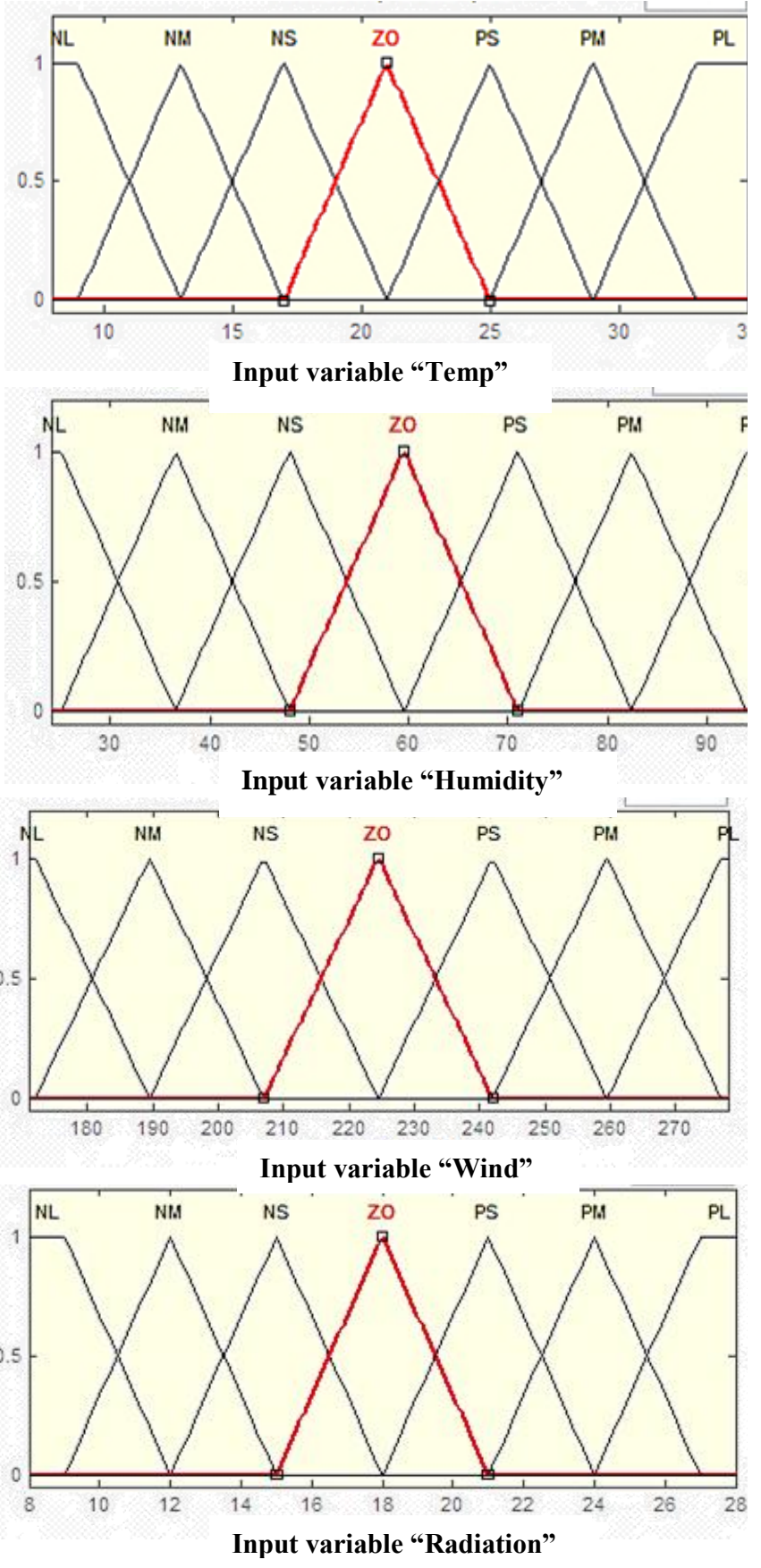

Figure 3 Membership degree of input variables

Fuzzy rule table is generated after setting the membership function. Part of these numerous rules is shown in Figure 4.

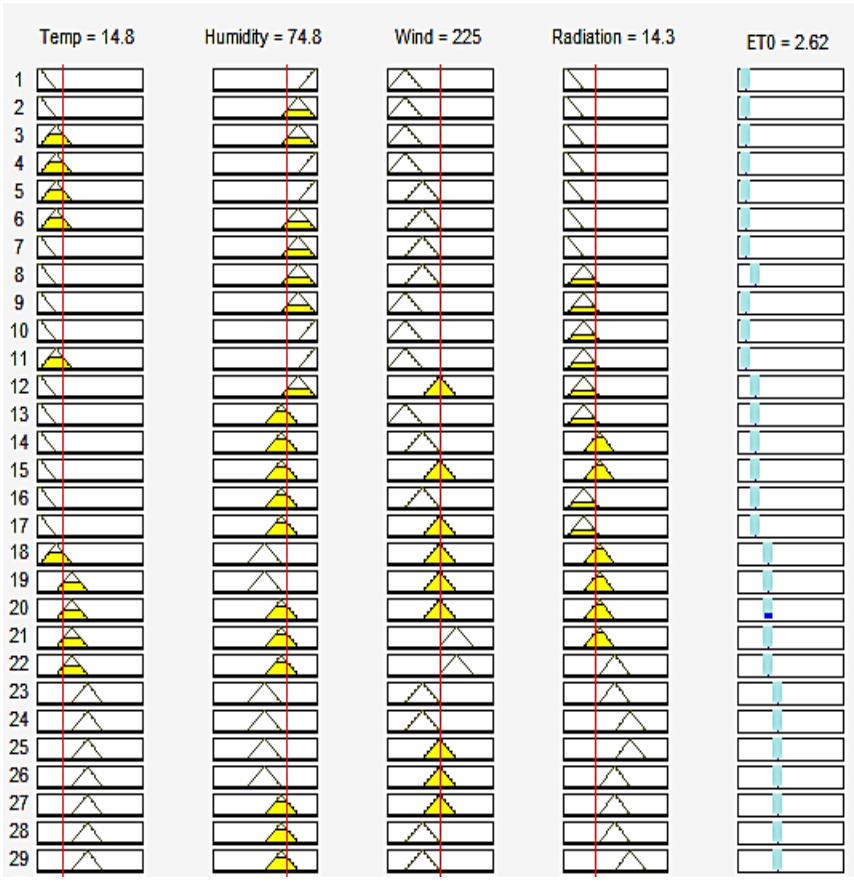

Figure 4 Part of the fuzzy rule table

\subsection{Soil Moisture Monitoring}

Soil moisture content is a crucial factor in determining required irrigation amount and irrigation schedule. Soil moisture concepts and real time monitoring method is demonstrated bellow:

\subsubsection{Soil Moisture Concepts and Terms}

Soil water availability refers to the capacity of a soil to retain water available to plants. The total available water in the root zone can be expressed as follows [1]:

$$
\mathrm{TAW}=1000\left(\theta_{\mathrm{FC}}-\theta_{\mathrm{WP}}\right) \mathrm{Z}_{\mathrm{r}}
$$

where TAW is the total available soil water in the root zone $[\mathrm{mm}], \theta_{\mathrm{FC}}$ is the water content at field capacity [m3 m-3], $\theta_{\mathrm{WP}}$ is the water content at wilting point [m3 $\mathrm{m}-3], \mathrm{Z}_{\mathrm{r}}$ is the rooting depth $[\mathrm{m}]$.

Readily available water is that portion of the available water that is relatively easy for a plant to use. It is common to consider about $50 \%$ of the available water as readily available water. $[1,13]$

$$
\mathrm{RAW}=\mathrm{p} \text { TAW }
$$

where RAW is the readily available soil water in the root zone $[\mathrm{mm}], \mathrm{p}$ represents average fraction of Total Available Soil Water (TAW) that can be depleted from the root zone before moisture stress (reduction in ET) occurs.

\subsubsection{Soil Moisture Monitoring Method}

Real time monitoring for soil moisture content could be achieved through simultaneously calculation for depletion ratio in soil moisture. This ratio should be prohibited from exceeding RAW amount, so as to avoid water stress occurrence. The percentage value of depletion in soil moisture could be calculated according to the formula:

$$
\mathrm{d} \%=\left(\left(\theta_{\mathrm{FC}}-\theta_{\mathrm{Cm}}\right) /\left(\theta_{\mathrm{FC}}-\theta_{\mathrm{WP}}\right)\right) * 100 \% \mathrm{~d}<\mathrm{RAW}
$$


where $\mathrm{d}$ is the percentage soil moisture depletion ratio, $\theta_{\mathrm{FC}}$ is the water content at field capacity [m3 m-3], $\theta_{\mathrm{WP}}$ is the water content at wilting point $[\mathrm{m} 3 \mathrm{~m}-3], \theta_{\mathrm{Cm}}$ is current soil moisture [m3 m-3].

\subsection{Estimation of Irrigation Amount Needed}

Irrigation quantity is crucial issue in precision agriculture, since it affects a crop yield and quality [9]. Estimation of irrigation quantity theory and implementation is depicted in the following two parts:

\subsubsection{Estimation of Irrigation Quantity Theory}

Required irrigation amount depends on several vital parameters. One of these factors is a crop water requirements $\left(\mathrm{ET}_{\mathrm{c}}\right)$, which could be estimated according to Eq. (6) [1]:

$$
\mathrm{ETc}=\mathrm{ET} 0 \mathrm{x} \mathrm{Kc}
$$

where ETc the crop water requirements [mm day-1], ET0 the reference evapotranspiration [mm day-1], Kc the crop coefficient.

The required net irrigation amount is estimated using $[1,10]$ :

$$
\mathrm{d}_{\mathrm{n}}=\left(\theta_{\mathrm{FC}}-\theta_{\mathrm{Cm}}\right) * \mathrm{Z}_{\mathrm{r}}
$$

where $d_{n}$ is current net irrigation amount $[\mathrm{mm}], \theta_{\mathrm{Cm}}$ is current soil moisture [m3 m-3].

Additionally, irrigation interval was calculated as [13]:

$$
\mathrm{II}=\mathrm{d}_{\mathrm{n}} / \mathrm{ET}_{\mathrm{c}}
$$

where II is irrigation interval (day), $d_{n}$ is net irrigation [mm], ETc crop water requirements [mm day-1].

\subsubsection{Estimation of Irrigation Quantity \\ Implementation}

Based on FIS, net irrigation prediction system is developed using Matlab. The input variables of fuzzy system are: ET0, the percentage ratio of depletion in soil moisture, as shown in Figure 5.

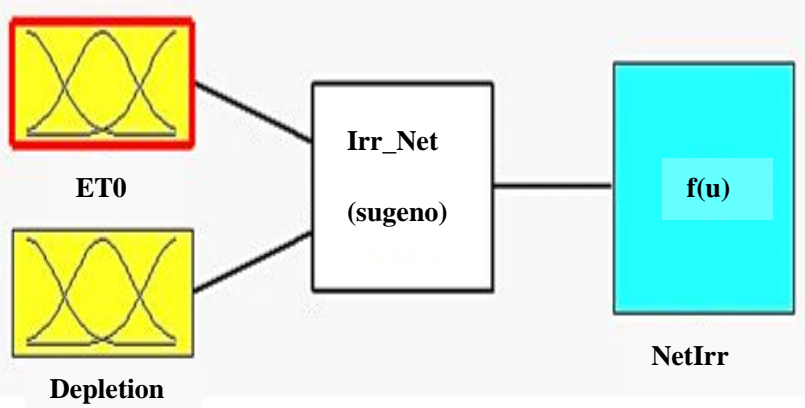

Figure 5 FIS for computing required net irrigation

The universes of discourse of input variable ET0 are $\{1.19,3.425,5.66,7.895,10.13\}$. Its fuzzy language values are VS (very small), Small (small), Medium (moderate), High (high) and $\mathrm{VH}$ (very high) $\}$. The universes of discourse of input variable depletion are $\{40,60\}$. Its fuzzy language values are $\{$ Small (small) and High (high)\}. Membership functions of input variables are shown in Figure 6.
The universes of discourse of output variable NetIrr are $\{0,92.4,94.5,97.6,98.6\}$. Its fuzzy language values are \{ZO (no irrigation), small (small), pSmall (relatively small), high (relatively high) and vHigh (very high)\}. Its membership function type is constant.

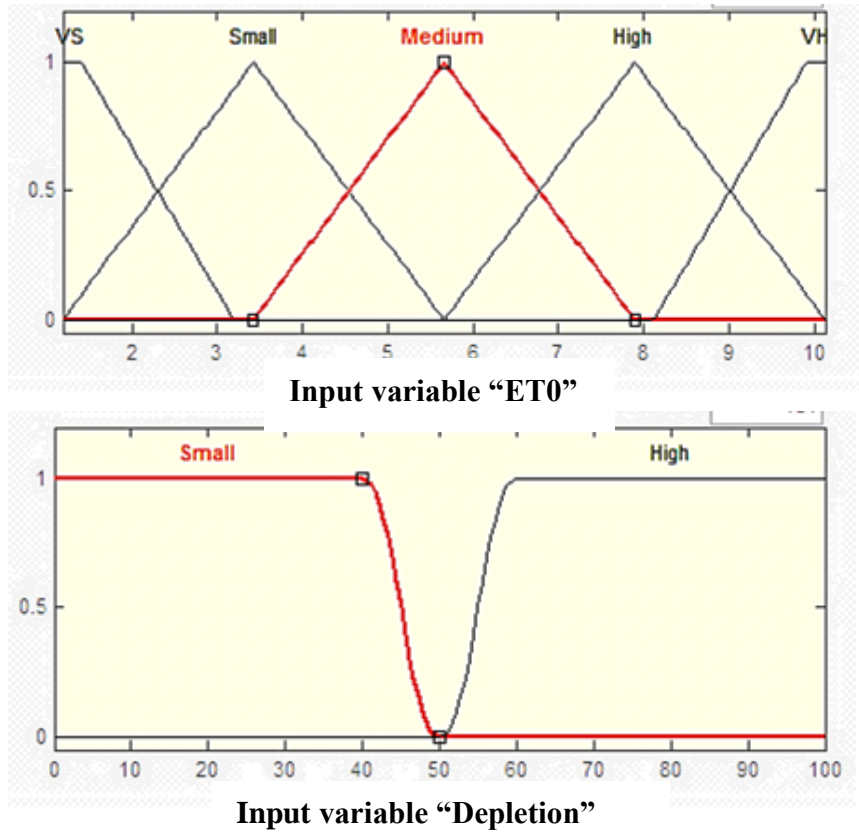

Figure 6 Miembersnip aegree or input variabies

The generated fuzzy rule table is shown in Figure 7.
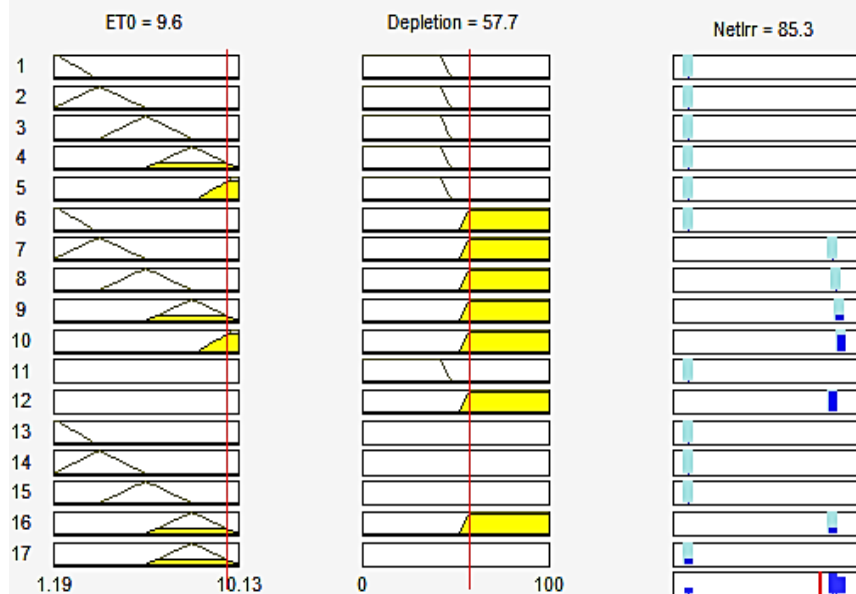

Figure 7 Fuzzy reasoning rule table

\subsection{Calculating Irrigation Time and Irrigation Schedule:}

Irrigation time $(\mathrm{T})$ is the time that it takes to apply the amount of irrigation water.

\subsubsection{For Drip Irrigation System:}

Time of irrigation on a management unit is calculated according to [13]:

$$
\mathrm{T}=\frac{\boldsymbol{d}_{\boldsymbol{n}}}{\mathbf{q} * \mathbf{N} * \mathbf{E}}
$$

where $\mathrm{T}$ is irrigation time [minute], $\mathrm{d}_{\mathrm{n}}$ is net irrigation [mm], $\mathrm{E}$ is system efficiency \%, $\mathbf{q}$ is nozzle discharge rate $[1 / \mathrm{s}], \mathbf{N}$ is number of nozzles. 
Since q, N, and E are constants which depend on the irrigation equipment information, the previous equation can be re-written as:

$$
\begin{aligned}
& \mathrm{T}=\mathrm{k} * \mathrm{~d}_{\mathrm{n}} \\
& \text { where } \quad \mathbf{k}=\frac{\mathbf{1}}{\boldsymbol{q} * \boldsymbol{N} * \boldsymbol{E}}
\end{aligned}
$$

\subsubsection{For Sprinkler Irrigation System:}

Time of irrigation is calculated according to Eq. (12) [13]:

$$
\mathrm{T}=\mathrm{d}_{\mathrm{n}} / \mathrm{p}_{\mathrm{r}}
$$

where $d_{n}$ is net irrigation $[\mathrm{mm}], \mathrm{p}_{\mathrm{r}}$ is precipitation rate of the sprinkler [mm/hour].

Eq. (12) could be re-written as in Eq. (10), except that $\mathrm{k}$ should be calculated according to Eq. (13):

$$
\mathrm{k}=1 / \mathrm{p}_{\mathrm{r}}
$$

Hence, Eq. (10) can be considered as a general equation for calculating irrigation time; $\mathrm{k}$ depends on the irrigation strategy and equipment information.

\section{Simulation ReSUlts}

Based on the fuzzy rule table, a surface plot of ET0 fuzzy prediction can be obtained, as shown in Figure 8. It shows that ET0 is gradually increased with the increasing of air temperature, radiation, and wind speed. In addition, it is decreased with the increment of relative humidity.
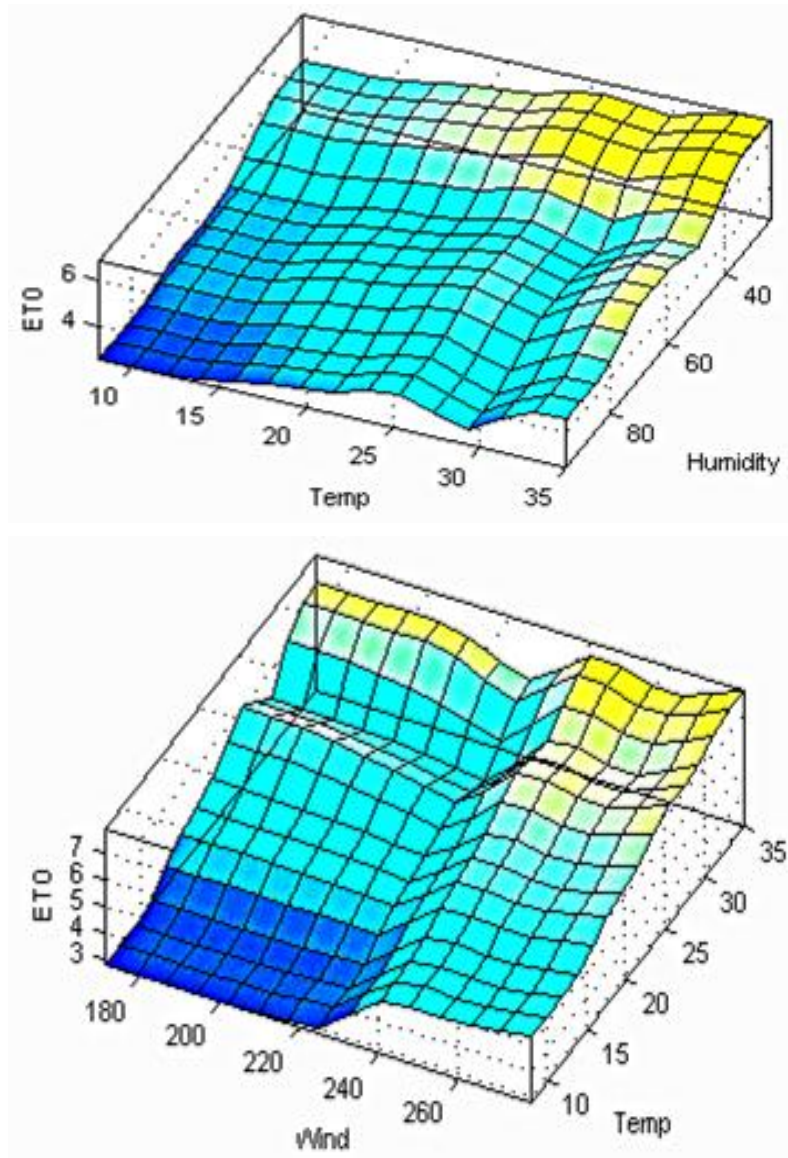

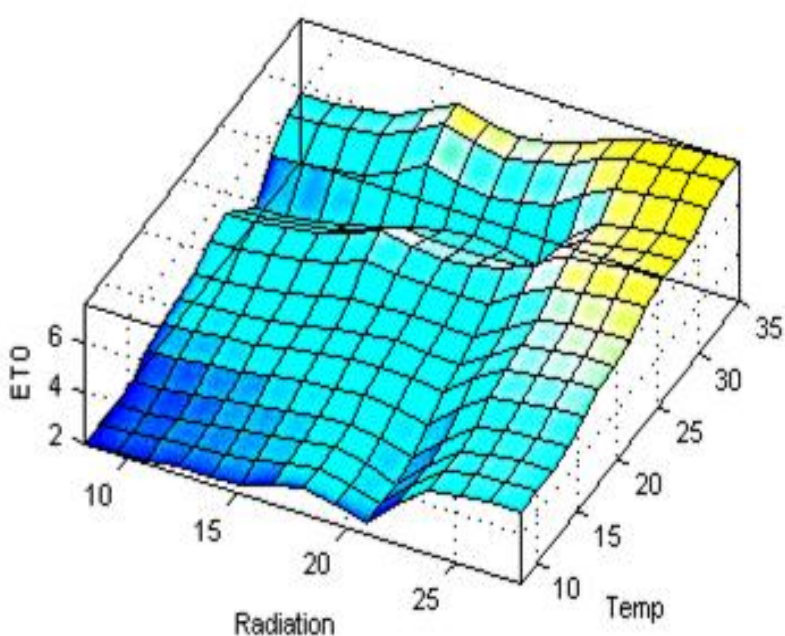

Figure 8 ET0 fuzzy predicting surfaces

Simulation results show that FIS is an accurate efficient tool for predicting and controlling irrigation amount. Fuzzy logic maps the imprecise variability in weather conditions to appropriate amount of irrigation needed to be applied.

The fuzzy reasoning result for predicting net irrigation is shown in Figure 9. It shows that the quantity of supplied irrigation water is increased rapidly with any increment in evapotranspiration. Moreover, Figure 9 shows that crop is irrigated, if and only if, the soil moisture depletion ratio reaches the specified depletion value. This value is supposed to be $50 \%$ of the total available water. Otherwise, if the depletion ratio was small, the soil still has a sufficient amount of water. Hence, crop does not need to be irrigated.

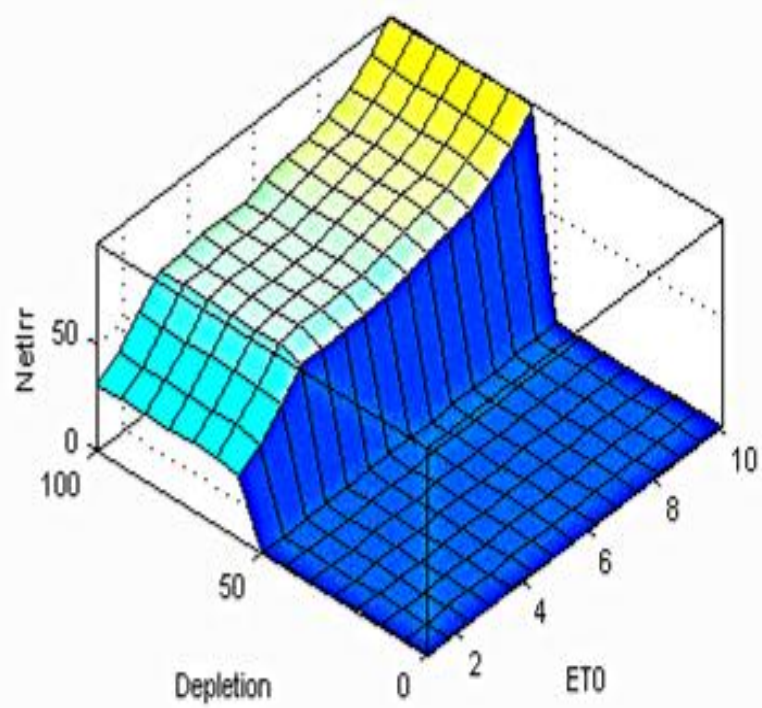

Figure 9 Net irrigation fuzzy predicting surface

Figure 10 shows the performance of our proposed model in terms of soil monitoring, evapotranspiration estimation and required irrigation amount. Part (a) demonstrates the results of soil monitoring mechanism which proved that soil moisture depletion never reaches $100 \%$ due to the use of FIS. This means that our model prohibits the soil water content from reaching the 
permanent wilting point, thus no water stress occur. Besides, when soil moisture depletion ratio reaches the maximum allowable depletion value, the irrigation system equipment is powered $\mathrm{ON}$ and valves are opened for a determined time period. Thus, it reduces the power switching. Hence it is thrifty in terms of power and water consumption. Moreover, the model is adaptive and adjusts its behavior according to parameters changes.

Part (b) demonstrates evapotranspiration estimation results, which depict that, ET0 is small in the first two months in addition to the last one of the year due to low temperature, slow wind speed, low radiation and high air humidity. Besides the small rate in ET0, there is a probability of rain falls during these months. Thus, soil remains moisturized for longer period as compared with the rest months of the year, as demonstrated in part (a). This reduces the need to apply irrigation during winter season, as shown in part (c), thereby conserves water resources.

In contrast, during summer season where rain falls is rare and evapotranspiration is very high, irrigation water is considered as the sole resource for providing soil with the required moisture content. Thus, frequent irrigation dosage is required. Hence, our system's behavior mimics the stand to reason behavior which shows its efficiency, adaptability and suitability for managing and controlling irrigation systems.

As well as, it well suits for various soil types, several crop kinds, broad range of locations, different irrigation strategies and equipment due to its consideration to soil, crop, and atmosphere conditions and other significant factors.

The simulation results prove that fuzzy model is a quick efficient tool for predicting evapotranspiration and the needed amount of water. Thus, indicating its suitability for water conservation and irrigation management.

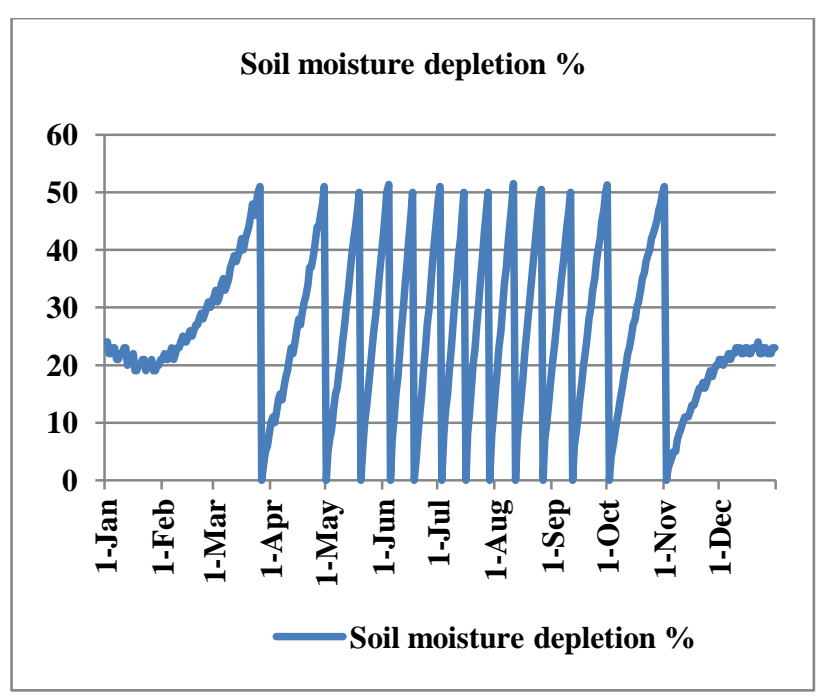

(a) Soil moisture depletion ratio change against time

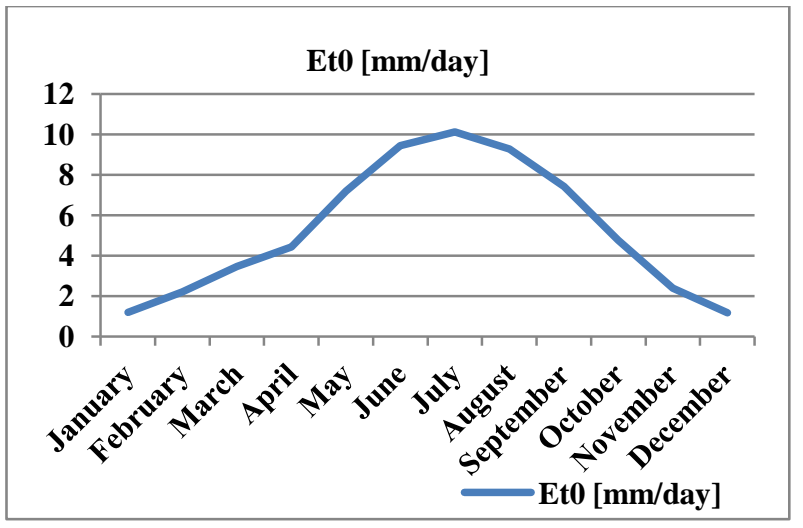

(b) Evapotranspiration change against time

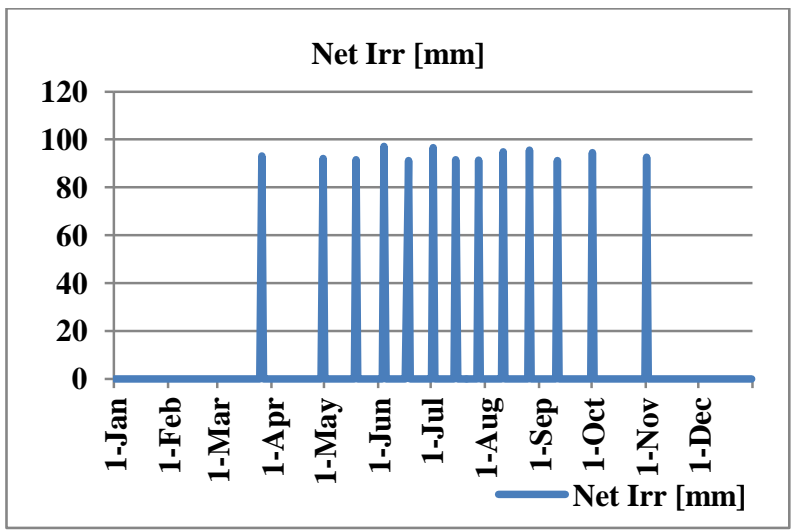

(c) Required net irrigation against time

Figure 10 System performance against time

\section{CONCLUSIONS}

An efficient irrigation system has been proposed. This system was based on the computed ET and the required water quantity. These parameters were evaluated using fuzzy inference methodology. Two jobs have been addressed by the proposed system; firstly it scheduled the irrigation, and secondly it evaluated the irrigation time to satisfy the requirements of plants. This was done by introducing two algorithms, worked for both irrigation methods; sprinkler and drip. The fuzzy inference has been adopted for high accuracy and quickness in calculating the evapotranspiration and required net irrigation. Simulation results showed the expected performance of the proposed system. They proved that depletion in soil moisture never reaches $100 \%$ due to the use of FIS. This means that our model prohibits the soil water content from reaching the permanent wilting point, thus no water stress occur. Besides, no irrigation occurs unless soil moisture depletion ratio reaches the maximum allowable depletion value which is equal to $50 \%$ of total available soil water.

\section{REFERENCES}

[1] Allen, R.G., Pereira, L.S., Raes, D., Smith, M., 1998. Crop Evapotranspiration: Guidelines for Computing Crop Water Requirements. FAO, Rome, p. 300 (Irrigation and Drainage Paper, 56).

[2] S.Muhammad Umair, R. Usman, 2010. Automation of Irrigation System Using ANN based Controller, International Journal of Electrical \& Computer Sciences IJECS-IJENS Vol:10 No:02 
[3] Xinrong Zhang, Bo Chang, 2012. Design of Watersaving Irrigation Monitoring System Based on CC2430 and Fuzzy-PID. Journal of Control Engineering and Technology (JCET), Vol. 2 Iss. 3, P. 124-129

[4] Xiaohong Peng, Guodong Liu, 2012. Intelligent Watersaving Irrigation System Based on Fuzzy Control and Wireless Sensor Network. Fourth International Conference on Digital Home

[5] Peng Xiaohong, Mo Zhi, Xiao Laisheng, Liu Guodong, 2009. A Water-saving Irrigation System Based on Fuzzy Control Technology and Wireless Sensor Network, IEEE

[6] Zheng Yao and Guohuan Lou, XiuLi Zeng and Qingxin Zhao, 2010. Research and Development Precision irrigation control system in agricultural, International Conference on Computer and Communication Technologies in Agriculture Engineering IEEE

[7] Xinrong Zhang, Bo Chang, 2012. Design of Watersaving Irrigation Monitoring System Based on CC2430 and Fuzzy-PID, Journal of Control Engineering and Technology (JCET) Vol. 2 Iss. 3 P. 124-129
[8] Nourani, V.; Mogaddam, A. A.; Nadiri, A. O., (2008a). An ANNbased model for spatiotempral groundwater level forecasting. Hydrol. Process, 22 (26), 5054-5066 (13 pages).

[9] T. Rajaee; S. A. Mirbagheri; V. Nourani; A. Alikhani, 2010. Prediction of daily suspended sediment load using wavelet and neurofuzzy combined model. Int. J. Environ. Sci. Tech, 7 (1), 93-110 (7 pages).

[10] Ketema Tilahun Zeleke and Leonard John Wade. Evapotranspiration Estimation Using Soil Water Balance, Weather and Crop Data. www.intechopen.com.

[11] Fuzzy Logic Toolbox ${ }^{\mathrm{TM}}$, User's Guide, 2014, www.mathworks.com.

[12] Shaohua Wan, 2012. Research on the Model for Crop Water Requirements in Wireless Sensor Networks. International Conference on Management of eCommerce and e-Government, IEEE.

[13] Iraqi Agribusiness Program, Irrigation Guidelines. 2012, www.inma-iraq.com. 